\title{
ESPAÇO SOCIAL, CULTURA E TERRITÓRIO: \\ O PROCESSO DE MICROTERRITORIALIZAÇAO HOMOERÓTICA
}

- BENHUR PINÓS DA COSTA ${ }^{1 \mathrm{~A}}$

\section{RESUM 0:}

0 ARTIGO OBJETIVA A ANÁLISE dOS PROCESSOS DE MICROTERRITORIALIZAÇÃO HOMOERÓtICA CARACTERIZADOS PELA PRÁtICA dO USO DE LOCAIS DE BAIXA MOVIMENTAÇ̃̃O POPULACIONAL. LOCAIS ESTES QUE SERÃO DESCORTINADOS EM FUnÇÃO dA dISCRIMINAÇÃO REALIZADA PELAS INSTITUIÇÕES SOCIAIS E PELA SOCIEDADE. 0 TEXTO, EM SUA ANÁLISE, RESSALTA A CONSTRUÇÃO, POR PARTE DOS HOMOSSEXUAIS, DE UMA GEOGRAFIA POSSIBILITADORA, UM ESTUDO DAS EXPRESSÕES PÚBLICAS, DOS DESEJOS E ESPONTANEIDADES HOMOERÓTICAS VISANDO À EFETIVA TERRITORIALIZAÇÃO DE UMA COMUNIDADE EFÊMERA/MOMENTÂNEA OU À FORTE AGREGAC̦ÃO DE LOCAIS, DELIMITADOS NO TEMPO.

PALAVRAS-CHAVE: TERRITÓRIO, TERRITORIALIDADE E MICROTERRITORIALIZAÇ̃̃O HOMOERÓTICA.

INTRODUÇ̃̃o

Este texto discute o espaço social. A ênfase ao adjetivo "social" implica numa atenção ao debate espacial da relação sociedade e indivíduo, aqui vistos como sujeitos sociais. Neste caso atentamos para a construção de "espaços de socialização" de indivíduos orientados para o mesmo sexo. A estigmatização dos desejos homoeróticos faz parte das determinações da sociedade, que estabeleceu uma "condição homossexual" (COSTA, 2002). Observando as oportunidades de socialização homoerótica, evidenciamos a ocorrência de microterritorializações que possibilitam o encontro destes sujeitos. Tais microterritorializações, por exemplo, entre muitas outras, de outros sujeitos sociais, se referem a um espaço social que não é exatamente sociedade, mas, ao mesmo tempo, todas as determinações dela e tudo que escapa a ela. Nesse sentido, os sujeitos homoeróticos encontram oportunidades de expressão de autenticidades na apropriação de partes do espaço social, microterritorializando aquilo que é discriminado pela sociedade. Pela emergência orgânica das autenticidades do espaço 
social (construído e construtor delas), as determinações e condições da sociedade vão se alterando num tempo mais lento. Sociedade e espaço social, assim, num recorte temporal do "agora", parecem antagônicos, porém a organicidade e fluidez do espaço social, de tempos em tempos, rompem com a rigidez da sociedade, alterando a própria rigidez de sua condição material, fazendo necessário outro suporte ideal do que se define como sociedade.

\section{A DIALÉTICA DO ESPAÇO SOCIAL}

Propomos a discussão do espaço social pela existência imbricada de suas contradições. Elas se apresentam da seguinte forma:

1) Homogeneidade:

a. Material: se refere à materialidade fria e funcional da sociedade urbano-industrial (LEFEBVRE, 2001, 2004). A monotonia do traçado e a praticidade dos arquitetônicos possibilitam a organização das vidas a partir do trabalho. Desde o século XIX as cidades passam por uma espécie de "reformismo racional" (WALLERSTEIN, 1995), que constitui uma estrutura que permita a fluidez do capital, o controle da população e a higienização. Nele se constroem objetividades disciplinares (FOUCAULT, 1984, 1993) - formas, procedimentos e ações - como a escola, o hospital, os hospícios, as prisões, as delimitações dos espaços das casas, das fábricas etc. O planejamento urbano e seu conteúdo racional, que preza a reprodução do capital no espaço urbano, estabelecido de maneira vertical (tecnocrático), torna-se ação fundamental dessa lógica (SOUZA, 2004)i

b. Ideal: inseridas numa objetividade material, as ações dos indivíduos são apreendidas conforme o funcionamento dessa objetividade (FOUCAULT, 1988), num conjunto de procedimentos necessários ao encaminhamento dos processos pautados na moralidade, no trabalho (HELLER, 1991) e nos papéis sociais (GOFFMAN, 1988, 1996). Os sujeitos, assim, agem de acordo com o funcionamento de uma "exterioridade" (BERGER\&LUCKMAN，2002) subjetivando as condições dela. Esta subjetivação implica referenciais construídos socialmente, como representações de si em torno da sociedade (MOSCOVICI, 2003). A isso se interpenetram uma genealogia da moral (FOUCAULT, 1993) e das funções e hierarquias do modo de produção.

c. A pretensão homogênea do espaço social gira em torno das condições material e ideal, acima apresentadas. O planejamento (do Estado/da empresa) é a ação máxima dessa pretensão, pautando organização racional de uma materialidade que condiciona a vida das pessoas no espaço. Esta vida é aceita e subjetivada mediante um sistema de funções e moralidades que estabelece as condições do "homem-particular" (HELLER, 1991) e do cotidiano (HELLER, 1991; LEFEBVRE， 1958).

2) Fluidez/dinamismo/organicidade: temos uma organização da sociedade como expressão do urbano, industrial e moderno, que produz as condições do homem-particular, cumpridor de funções e alienado perante a complexidade organizacional da materialidade e das representações morais e funcionais das identidades sobre si. Por outro lado, tudo isso se processa de forma incompleta e, aquém de uma pretensa modernidade/organização racional do espaço e da 
vida das pessoas, mais temos um processo de modernização incompleta e hesitante (TOURAINE, 1994). A sociedade - máquina (peças e encaixes bem feitos e engrenagens perfeitas) somente apresenta-se como condição ideal. A idealização dela estabeleceu processos objetivos incompletos, excludentes e repressivos, que ocasionaram múltiplas contestações e singularidades outras, não apreendidas na sua totalidade. Temos assim inúmeros sujeitos conscientes de si (WEBER, 1995; SIMMEL, 1973) como singularidades (DELEUZE \& GUATTARI, 1995) - de seus desejos, suas espontaneidades, suas discordâncias e contestações, seus sofrimentos, seus sintomas de alta e baixa estima, suas autenticidades e a negação de suas identidades que constroem e praticam um espaço social orgânico, de múltiplas formas e vivências, assim como estabelecem outras representações de si além daquelas pretensas pela moralidade e identidades sociais pré-estabelecidas nas instituições sociais formais. O cotidiano apresenta-se assim pelas "artes do fazer" (DE CERTEAU, 1994) no qual os "fracos" apresentam táticas que burlam, contestam, de forma silenciosa, e reinventam as condições das estratégias que organizam o lugar.

3) Em relação aos sujeitos orientados para o mesmo sexo, não existiria espaço para eles ou ele não é bem vindo nas instituições sociais. Concorre a isso um sistema de representações sociais que estigmatiza e condiciona os homossexuais a desviantes (COSTA, 1992; COSTA, 2002; MOTT, 1988). A vida social é herança de uma sociedade patriarcal cujo modelo é a instituição familiar (GIDDENS, 1993) e as condutas heterossexuais são pautadas nos padrões de gênero sexual (BUTLER, 2003). Por outro lado, os ditos "homossexuais" burlam os sistemas de organização da sociedade (DE CERTEAU, 1994), produzem rizomas (DELEUZE \& GUATTARI, 1995) de sociabilidade e se apropriam de partes do espaço social - alterando sua forma, função e representação - para se encontrarem e discutirem sobre suas condições. Tais discussões encontram autenticidades múltiplas sobre as vivências e representações da sociedade.

\section{O PROCESSO DE MICROTERRITORIALIZAÇÃO HOMOERÓTICA} COMO EVIDÊNCIA DA CONSTRUÇÃOO ORGÂNICA/FLUIDA/ DINÂMICA DO ESPAÇO SOCIAL

A seguir apresentaremos a ideia sobre o processo de microterritorialização homoerótica. Este processo representa uma proposta de entendimento da relação sociedade-indivíduo-espaço, no qual as microterritorializações resultantes são "projetos" territoriais espontâneos de sujeitos homoeróticos em escala muito grande, mas que carregam, ao mesmo tempo, todo peso das determinações sociais. Dessa forma, tais microterritorializações não constituem fronteiras definidas, sendo elas fluidas, e se apresentam pela apropriação tênue de partes do espaço social constituído (que se pretende homogêneo), alterando o uso e a representação desta parte, assim como construindo uma forma ou alterando a existente. A microterritorialização institui a relação sociedade-indivíduo-espaço e expressa a cultura ou as práticas - interações corporais (ações, gestos, condutas, jeitos e acessórios corporais) estabelecidas - e representações - ideias e identificações sobre o eu e os outros - dos sujeitos orientados para o mesmo sexo. Na microterritorialização o espaço se "eleva" 
em relação à sociedade e ao indivíduo, sendo que a cultura estabelecida nem é propriamente sociedade, nem exclusivamente definições individuais da interação, mas, ao mesmo tempo, as duas coisas relacionadas e tornadas autênticas pelas interações do "aqui" e "agora" (MAFFESOLI, 2002). A cultura aqui é a (micro)território(lização) lembrando (e alterando um pouco) a ideia de Geertz (1989). As microterritorializações são rizomas (DELEUZE; GUATTARI, 1995) que alteram a pretensa homogeneidade das ações e formas do espaço social. Elas instituem as táticas que rompem com as estratégias que definem o próprio lugar (DE CERTEAU, 1994). Porém, tais estratégias são duras demais para serem rompidas, tornando as táticas os movimentos silenciosos no campo do inimigo: antes, o lugar como produto da sociedade, como externalidade ao sujeito e que deve ser apreendida, dobrando-o; agora, o lugar reinventado e reconstruído como obras dos sujeitos interagindo devido às representações de $\mathrm{si}_{i}$ ao mesmo tempo o "agora" partindo dos pressupostos instituídos pela própria sociedade, sendo o fundamento das reinvenções dos sujeitos, que estabelecem a cultura (microterritorialização) que se eleva em relação a ele e à sociedade.

Em relação ao que estamos argumentando, vamos descrever o processo de microterritorialização homoerótica. O texto está organizado em etapas do processo. Não necessariamente as etapas seguem esta ordem. Colocamo-las como discussões que devem ser revistas por outros estudos. A cada etapa argumentamos sobre um processo geral, que pode ser usado para qualquer outra singularidade social, e, posteriormente, sobre a especificidade homoerótica.
1) No espaço social ocorrem singularidades em desacordo, que não cumprem efetivamente os scripts morais ou papéis sociais (GOFFMAN, 1996), e rompem com a previsibilidade das cenas sociais. Aqui temos projetos de si incompletos, sem sucesso ou contestados (VELHO, 1989, 2004), uma vez que os projetos de si não são exatamente de si, mas de um sistema reprodutor de situações possíveis de si, sendo forçados pelas instituições sociais em contextos ideais e materiais possíveis. Neste aspecto, ocorre a ideia de "homossexual" como desviante (COSTA, 1992; COSTA 2002), como incapaz de cumprir com os preceitos de si impostos pela sociedade. O homossexual torna-se uma polarização identitária estigmatizada (GOFFMAN, 1988), assim como, ao mesmo tempo, inúmeras situações, singularidades e contextos homoeróticos se produzem em torno da homossexualidade, constituindo outros projetos e identificações de si, além de uma pretensa unidade/polaridade homossexual e heterossexual.

2) A sociedade, então, cria situações identitárias para organizar as singularidades em desacordo. Neste foco, como vimos, ocorrem polarizações entre padrões e desvios sociais, no sentido de organizar a vida em sociedade, de acordo com preceitos morais. O homossexual, então, é um sujeito estigmatizado, que sofre com a determinação identitária do polo desviante do normal heterossexual.

3) As criações ideais geram desvios que não são aceitos socialmente. As pessoas acabam se impregnando de ideias sobre as outras e agem de acordo com as coisas socialmente aceitas. Os 
sujeitos orientados para o mesmo sexo têm como refêrencia social a condição de desvio e as determinações sobre os gêneros sexuais. Ocorre um contorno de uma cultura gay, impregnada de representações criadas (COSTA, 1992; COSTA, 2008a) desde a medicina do século XIX até a literatura do século XIX (Proust, Gide, Balsac) e a publicidade da passagem do século XX ao XXI (algumas revistas de circulação nacional como Homens e Sui Generis, nos anos 90, e agora as revistas DOM e AIME) que produzem representações dialéticas entre transgressão às regras e dogmas sociais e a reprodução de elementos da grande cultura e do consumo, muitas dessas reproduções adequadas à manutenção das definições dos gêneros sexuais ou às divisões/ definições de papéis e estéticas entre masculino e feminino.

4) Os desvios são condições de existência apreendidos socialmente nas instituições sociais (família, escola, amigos, sistemas de aprendizados informais, trabalho, profissões, espaço público etc.). Tais instituições definem os modelos a seguir e a não seguir e estabelecem elementos articuladores dos projetos de si (VELHO, 2004). Os projetos são condicionados a tramas de sujeitos e instituições avaliadoras que, de forma mais brusca e repressora, ou pela sutileza das negações e discriminações, vão selecionando aqueles mais aptos a participar efetivamente da sociedade. Aqueles cujos desejos e espontaneidades não se adequam aos elementos definidores dos projetos de si, aceitos socialmente, vão sendo aos poucos excluídos de uma série de participações sociais e acabam produzindo outros espaços de sociabilidade que não são exatamente sociedade, mas algo que ela deixou à margem, aos excluídos dela. Estas exclusões se referem a vários níveis de potencial participação na sociedade, lembrando a relação da capacidade financeira de participação, assim como a educacional e também a relativa às identificações e condutas dos sujeitos, se se referem ou não aos elementos de personalização importantes em certas interações sociais.

5) São muitas as espontaneidades que não se encaixam nos projetos sociais sobre o si. Muitas delas são, em algum momento da formação da personalidade do sujeito, ainda não identificadas ou não significadas por ele. Pela sensibilização em relação à falta de oportunidade num quadro social de referência, os sujeitos dão significado a elas em relação às mesmas existentes no quadro social de referenciais (moralidades e condutas aceitas). O sujeito orientado para o mesmo sexo significa (WEEKS apud PLUMMER, 1999) os preconceitos e discriminações que sofre em relação aos próprios determinantes sociais que movem tais preconceitos. Pode, assim, viver no sofrimento e tentar enquadrar-se aos modelos sexuais aceitos (muitas vezes levando uma vida sexual e afetiva dupla) ou toma uma atitude de aceitação de si mesmo e agregação a uma cultura desviante pelo encontro com outros em lugares de frequência homoerótica (COSTA, 2008). A aceitação radical pode levar à reprodução radical da representação das condutas que geram o preconceito, como, por exemplo, as atitudes "fechativas" (PARKER, 2002), que se referem à exacerbação do feminino no corpo masculino e à expressão pública disso, no sentido da transgressão e da vontade de perturbar o bom senso de comportamento em espaço público.

6) As espontaneidades encontradas entre a 
sociedade se transformam efetivamente em sociedade quando são apresentadas como identidades possíveis ou não - possíveis. Em relação às não - possíveis, temos as desviantes aos padrões aceitos e, como desvios, permitem a volta do sujeito aos caminhos corretos (pelo cultivo, a educação e a discriminação). Os sujeitos apresentam espontaneidades não aceitas, as significam como desviantes perante desvios construídos socialmente e introjetam um estigma (GOFFMAN, 1988). Os identificados como homossexuais sofrem pela impossibilidade de expressar seus desejos no espaço público.

7) Sujeitos homoeróticos não conseguem fugir da espontaneidade agora significada e também não conseguem se abster das imposições identitárias e discriminatórias do quadro social de referências. Em si cambiam condições existenciais (criam uma flexibilidade de si) em relação às diferentes cenas e interações sociais, tornando os discursos sobre sua sexualidade uma constante encenação. Os sujeitos orientados para o mesmo sexo constroem uma geografia de possibilidades de expressão dos desejos e espontaneidades homoeróticas, unindo localizações de níveis variados de velação e revelação dessas espontaneidades, interagindo sutilmente em espaços públicos a fim de exercer tais desejos.

8) As espontaneidades identificadas por um estigma lutam pela existência social, mas são segregadas em territórios existenciais - as condições da identidade desviante são subjetivadas e acabam delimitando as motivações, as percepções sobre desejos e as sensações afetivas do sujeito - e concretos - em relação à delimitação espacial das possibilidades de agir em torno do homoerotismo.
Os desejos homoeróticos são diversos, mas muitos sujeitos acabam estabelecendo restrições desejantes entre ativo e passivo no ato sexual, que implica, muitas vezes, a reprodução dos papéis e estéticas de masculino e feminino. No espaço urbano as relações homoafetivas se estabelecem em lugares de baixa circulação populacional, como ruas escuras, pontos mais arborizados de parques e praças em momento de baixa circulação populacional, assim como em casas noturnas exclusivas a estas convivências. Atualmente a visibilidade pública homoerótica implica a efetiva territorialização de uma "comunidade efêmera/ momentânea", ou uma forte agregação em partes do espaço, também delimitada no tempo. As afetividades homoeróticas ocorrem visivelmente principalmente em lugares caracterizados pela diversidade cultural e cosmopolitismo, muitos deles incentivados pela frequência turística ou de eventos pautados na cultura gay, como as paradas gays. Na banalidade do cotidiano elas se estabelecem camufladas por entre a multidão urbana ou em períodos de baixa circulação do centro da cidade ou em parques. A visibilidade territorializada é comum em algumas praias das grandes cidades litorâneas do Brasil, muito frequentadas por turistas que estão fora de seu cotidiano local repressivo, como, por exemplo, o famoso posto 9, na Praia de Ipanema, o bar Aruba, em Salvador, e o bar do Deca, em Florianópolis (Praia Mole). Em algumas praças também ocorre visibilidade afetiva homoerótica protegida em momentos de grande circulação de diversidades expressivas urbanas, como no Parque da Redenção, em Porto Alegre, nos domingos à tarde. Interessante que a visibilidade homoerótica da 
Redenção é protegida pela existência próxima de muitos "malucos" sociais (punks, rockers, neohippies), cujas expressões homoeróticas se misturam por entre estas "maluquices" e são toleradas e banalizadas. Efetivamente a Redenção é um parque constantemente frequentado por sujeitos orientados para o mesmo sexo (COSTA, 2008), que se territorializam de forma discreta por entre os recantos, entre as árvores, na noite, ao meio - dia ou cedo da manhã e em dias de chuva. Somente no domingo há visibilidade que se reforça pelo contato com outras diversidades tantas do lugar. $\mathrm{Na}$ normalidade cotidiana do parque há a necessidade de velar as expressões e interações homoeróticas.

9) As espontaneidades são compartilhadas e formam agregados sociais estabelecidos em algum lugar. Ocorre a apropriação de algum lugar tornado, assim, território de compartilhamento e proteção em relação às situações estigmatizantes da sociedade, de sujeitos conscientes de si (do desejo, do estigma e das determinações da sociedade) que criam e recriam atributos de uma identidade a partir de suas práticas e representações culturais sobre os atributos de si (espontaneidades, identidades, desvios e quadro social de referências). Transformam-se, assim, em singularidades. Além das tramas cotidianas envolvendo o homoerotismo e suas relações, e destacando entre seus elementos a busca de parceiro sexual, criam-se afetividades (grupos de amizade e relações duradouras) cujos propósitos são as discussões sobre as suas existências e situações do dia-a-dia. Estas singularidades em interação são possibilitadas pela microterritorialização do encontro homoerótico.
10) Apresentamos o mercado como uma perturbação dialética neste caso, ou seja, "dentro" e "fora" da sociedade. O mercado move-se dentro de um quadro social, entre normas e contra normas, padrões e desvios, aproveitando-se da rentabilidade em todos os veios da organicidade do espaço social. O mercado trabalha com o desejo e a diversidade (BENKO, 1996) e se desagrega dos propósitos de uniformização social, buscando diferentes grupos e diferentes possibilidades de rentabilidade. Em relação a isso se criam fortes apelos midiáticos múltiplos de promoção dos desejos humanos diversos, imersos em elementos estéticos referentes a certas práticas e representações culturais até então não vistas de forma tão clara, muitas delas tornadas fetiches. $\mathrm{O}$ experimento e a reinvenção tornam-se processos do imperativo da criatividade no viver cotidiano, principalmente como elemento atual no trabalho flexível da prestação de serviço, do mundo da comunicação e entretenimento, dos mercados de cultura e da classe média urbana, que declara os sujeitos como seres responsáveis de si na busca de se destacar criativamente neste novo contexto (PRATA, 2004). A criatividade atrela-se à valorização das espontaneidades tornadas possibilidades de identificações diversas no mundo urbano cosmopolita, gerando, assim, circuitos múltiplos de agregações estéticas efêmeras, atreladas à flexibilidade do consumo do/pelo desejo, cujo relações estabelecidas se vinculam à representação narcisista dos sujeitos em interação (MAFFESOLI, 2002).

11) Os guetos homossexuais se abrem às trocas de elementos estéticos nessa nova cultura de consumo da diversidade e criatividade expressiva. 
O desejo homoerótico se agrega a práticas e representações diversas, fetichizando o masculino e o feminino, atrelando-se à mídia, à música, ao espetáculo globalizado, às culturas subversivas tornadas possíveis pelo mercado e ao experimento estético múltiplo, tornado pastiche (BRAGA JUNIOR, 2006). Ocorre a possibilidade de agregação de mais e mais sujeitos relacionados à espontaneidade e identidade estigmatizada. Muitas vezes o estigma é suavizado pela camuflagem dele em relação a algum atributo estético captado pelo mercado da diversão (eventos, festas noturnas), que identifica a territorialização como próxima à arte e a expressões inovadoras da cultura globalizada (são exemplos as festas rave, clubbers, de música eletrônica, e relacionadas à moda). Antes disso, a boemia homoerótica é captada pelo mercado ante a deriva constante entre bares noturnos. A visualização de alguns comerciantes a respeito da possível rentabilidade dos serviços especializados a este público e o movimento globalizado da disco music, tornada expressão cultural de diversão noturna possível nos anos 1970, invadem a noite das grandes cidades e iniciam a construção de um conjunto de práticas e atributos referentes a uma cultura gay. ${ }^{22}$

12) Então a relação espontaneidade, estigma, identidade, quadro social de referências, expressões estéticas de tribos urbanas (MAFFESOLI, 2002), agregações homoeróticas territorializadas é reforçada pelo mercado, que constrói territórios de consumo (materiais, como lugares de frequência; ideais, como gostos, condutas e estéticas preferenciais) que intensificam relações entre sujeitos imersos numa condição estigmatizada. $\mathrm{O}$ estigma persiste em relação à banalidade do cotidiano, mas nas microterritorialização permitemse várias condições estético-expressivas do homoerotismo, muitas delas imbricadas ou tornadas terceiras culturas (FETHERSTONE, 1995), como o caso dos emos, pela livre circulação criativa dos indivíduos presentes. A possibilidade públicoprivada (aberta-fechada, semi-pública, semi-privada) amplia as trocas simbólicas entre sujeitos homoeróticos.

13 ) As pessoas criam suas relações nessas microterritorializações, e tais relações são disseminadas pelo mercado, assim como o mercado, a partir da publicidade, da música, do videoclipe, da moda, criam possibilidades expressivas do homoerotismo, num equilíbrio estético complexo entre afirmação/exercício de um desejo e a necessidade de amenização de um estigma. Cria-se uma pretensa cultura que se pretende homogênea, a cultura gay, mas, além de uma identificação restrita dela, o que mais se observa é o pastiche referente à instabilidade estética e interacional dela (BRAGA JUNIOR, 2006). Certos elementos das agregações homoeróticas territorializadas nos EUA se ampliam, acompanhando a globalização cultural norte-americana (PARKER, 2002), produzindo uma cultura gay que se pretende unificada em âmbito global, cujo elemento chave de permanência, divulgação estética, afirmação de práticas, representações culturais, afetividades e propostas mercadológicas são as paradas gays.

14) No processo ocorre um dilema entre a diversidade de práticas e representações cotidianas a respeito do homoerotismo, estabelecido pelos diversos sujeitos a respeito de suas ações e 
entendimentos sobre si, e uma pretensa uniformidade representativa de uma cultura gay, estabelecida por uma imaginação identitária sobre o ser gay (desde a literatura do século XX à mídia e publicidade do século XXI). A imaginação gay implica em recriações dos referenciais sexuais estabelecidos socialmente, instaurando uma subversão de práticas e representações sobre o feminino e masculino, cujo lema básico é a transgressão das estéticas e condutas de gênero na expressão dos corpos. Isso torna gay um grupo social imaginado, no qual tal imaginação fora reforçada pelo movimento gay, pela publicidade de autoaceitação (vide revista Sui Generis, nos anos 1990, discutido por MONTEIRO, 2000) e pela "cultura alternativa do arco-íris" representada nas paradas gays: "sair do armário", assumir-se, reinventar as condutas dos gêneros, estabelecer transgressões sexuais, o culto ao masculino e a reinvenção do feminino, a dança frenética e a música eletrônica, a alegria exacerbada e a ironia sobre a vida tornam-se elementos fundamentais que definem os indivíduos deste grupo.

15) O compartilhamento de uma identidade, a existência de territorializações e práticas de convivência e a difusão mercadológica e publicitária de elementos de uma cultura, criam uma comunidade alternativa. Ser gay é um modelo de vida alternativo à grande sociedade. Existe uma reprodução supracultural que torna envolvido o ser gay a um grupo social representante de uma cultura alternativa.

16) Inseridos nesta comunidade alternativa, que mais se explica pela existência localizada e fragmentada (PARKER, 2002; COSTA, 2008) de microterritorializações que concentram o dilema entre diversidades expressivas e a unicidade representativa de seres gays, os sujeitos homoeróticos debatem sobre suas condições e contestam o quadro social existente. Emergem nessas microterritorializações sujeitos políticos que se tornam elementos fundamentais dos movimentos organizados que lutam pelos direitos dos gays, assim como também aqueles produtores de cultura na mídia, na moda e na publicidade. Tais sujeitos formam um grupo que decide em relação aos determinantes de uma supracultura que indica expressões a serem absorvidas e construídas na concretude das relações dos seres Gays. Vimos assim um caminho de duas vias entre localização das práticas e representações que se pretendem unificadas no "aqui" e "agora" das relações gays e a construção ideal do ser gay, que compõem uma supracultura das mídias, publicidades, eventos, paradas gays e literatura.

17) Ao mesmo tempo, a condição de um padrão cultural de valorização de um estigma relacionado a um modo de vida alternativo não condiz com a realidade dos diferentes sujeitos. A relação midiática e festiva torna-se espetacularizada (DEBORD, 1997) no tempo e no espaço das festas e das paradas gays. Às identidades (normais e desviantes) tudo escapa. Em relação ao homoerotismo criam-se singularidades expressivas, ou seja, agregações e práticas espaciais múltiplas que contradizem as normas do quadro de referenciais e, de forma dialética, se aproximam deste mesmo quadro, além de serem influenciadas pelas condições de homogeneização de um movimento de valorização dos desvios (cultura gay) - que criam uma comunidade identitária que requer o público e o 
direito de cidadania. Assim, ocorrem situações diversas e inusitadas quanto ao homoerotismo. Como os sujeitos se comportam e se expressam em relação a estes desejos e ao quadro social de determinações? Isso indica um campo de possibilidades. Como são as práticas, representações em espaços de interação? Isso se abre para situações espaciais-temporais muito diversas.

18) Nesse processo múltiplas singularidades existem e elas criam situações e lugares de compartilhamento múltiplos que ora tendem à clandestinidade, ora à abertura proporcionada pelo mercado e imbricações estéticas entre outras tribos urbanas, ora a manifestações próximas às condições do quadro social (homoerotismo permeando alguns meios heterossexuais). Ocorrem dentro da interação/territorialização da relação estigma/comunidade múltiplas situações orgânicas que são, ao mesmo tempo, práticas culturais, expressão de singularidades e representações diversas sobre si. Assim ocorrem múltiplas microterritorializações homoeróticas em relação a este debate.

\section{TERRITÓRIO E ESPAÇO SOCIAL, POR UMA CONTINUIDADE} DO DEBATE. .

Ao que argumentamos até então, o espaço social se apresenta como condição primeira, representando a homogeneidade funcional e moral. $\mathrm{O}$ (a) (micro)território(alização) se apresenta como condição segunda, sendo o elemento contestador e orgânico, constituindo outras apropriações no espaço social, ao mesmo tempo "a favor" e "contra" (COSTA, 2007) a condição primeira. O espaço social emerge, então, como condição terceira, agora nunca visto como homogêneo, mas produto misto de forças de homogeneização e forças de diversificação, ou seja, orgânico. A microterritorialização contém aquilo que se referencia à sociedade, aquilo que é desvio dela (identidade desviante, estigma) e aquilo que escapa às duas coisas (espontaneidades e singularidades múltiplas em agregações territorializadas).

O espaço social contém a sociedade (COSTA, 2008b), ou seja, a norma, a condição de homogeneidade, os padrões, a racionalidade unificadora, a moralidade, a organização da vida, o homem agindo para a sociedade, que representam um quadro de referência do bem viver, da aceitação das condições naturalizadas como corretas. A sociedade apresenta padrões de unificação cultural, sendo cultura aqui como sociedade e um quadro de práticas e referências/representações aceitas socialmente. Nesse sentido, temos a condição da homossexualidade como desvio à norma, devendo ser combatida socialmente.

O espaço social também contém a representação da natureza (COSTA, 2008b), ou seja, as espontaneidades, os instintos, os desejos, as percepções múltiplas e as contestações às normas, assim como as alteridades diversas que contrapõem os quadros de referências sociais. As espontaneidades homoeróticas persistem em sujeitos sociais e são algo aquém da sociedade, portanto, mais condizentes ao polo natureza, oposto à sociedade.

O espaço social também contém a comunidade (COSTA, 2008b), ou seja, as relações dialéticas entre sociedade (normas, padrões, quadro de referências) e natureza (espontaneidades, instintos, prazeres, diferentes e autênticas percepções de si), produzindo comunidades territorializadas "a favor" e "contra" a 
sociedade (COSTA, 2007) de sujeitos agindo para si e seus companheiros (WEBER, 1995). Aqui cultura apresenta-se em seu caráter orgânico, estabelecido pelos questionamentos dos sujeitos sociais em relação aos seus desejos e determinações, assim como o compartilhamento de seus dramas. Nas contradições entre sociedade e natureza, em relação aos desejos homoeróticos, emerge o homossexual como sujeito dialético. Deles são produzidas comunidades que vão servir para aprisioná-los, separá-los da sociedade, mas que acabam sendo condições múltiplas que questionam os determinantes sociais e produzem outras formas/ideais sobre a própria sociedade.

O espaço social também contém a relação espaço e tempo (COSTA, 2008b), pois dentro da uniformização da sociedade existem contradições em relação a um processo desigual (hesitante, de perturbações, devido a contestações, de divisão territorial das funções e de esquecimento) da sociedade. Assim ocorrem múltiplas culturas estabelecidas e múltiplos territórios singulares, que reforçam e permitem a existência dessas culturas que, ao mesmo tempo, são elementos da uniformização e daquilo que as diferenciam (as espontaneidades dos sujeitos). As agregações de sujeitos homoeróticos se territorializam no tempo e no espaço: em relação às interações que se estabelecem no "aqui" e "agora", ou seja, nunca uma festa gay é igual à outra, ela se refere à condição existencial de cada sujeito que se apresenta a ela, a trama de condições que a identificam e estabelecem seus propósitos e as dialéticas existentes: entre unificação cultural gay e o pastiche de suas expressões; e entre os determinantes que estigmatizam a identidade homossexual e as condições autoafirmativas e contestadoras das práticas em relação ao homoerotismo.
Assim sendo, temos um espaço social orgânico, que é expresso por múltiplas microterritorializações. Tais microterritorializações são partes do espaço social como elementos de um sistema de interações entre outras partes e entre as condições de sociedade, comunidade, natureza, espaço e tempo. Elas dão forma às interações dos sujeitos e possibilitam suas existências. Os aprisiona (pois não fazem parte de um espaço social que se pretende unificado), pela negação a eles do espaço público, e os liberta (pois possibilita a construção de autenticidades que buscam o reconhecimento no espaço público). $\mathrm{Na}$ microterritorialização se produz/se transforma/se amplia, ou não, o contexto cultural dos sujeitos sociais (suas práticas e representações). Ao mesmo tempo, esta cultura envolve múltiplas existências em interação e, assim, ela tem uma relação com o acontecimento territorializado, ou seja, o espaçotempo cultural, que é efêmero.

\section{NOTAS}

1 Professor Adjunto do Departamento de Geografia da UFAM. Doutor em Geografia pela UFRGS. Pesquisador dos seguintes grupos de pesquisa CNPq: Geografia da Amazônia: ambiente e cultura (UFAM); O estudo do espaço social e suas transformações, implicações sobre a territorialidade e a gestão territorial (UFRGS) ${ }_{i}$ Geografia: cotidiano, território, ambiente e educação na cidade (ULBRA).

2 Pollak (1983, pp. 67 a 73 ) anuncia características marcantes da cultura gay, cultuada nessas territorializações:
1) fundada na clandestinidade;
2) gírias gays, elaboradas nos EUA, constituem um vocábulo cheio de nuanças sobre o amor, a paquera, mas também a timidez, a angústia e o cinismo agressivo;

3) uso de nomes próprios femininos e diminutivos pretensiosos, indicando ironia na autorepresentação; 4) uso de trejeitos afeminados e estilos femininos,
humorizando o estereótipo como construção de uma
identidade, em tempos de maior opressão,

5) com a ascensão dos movimentos gays e a diminuição da opressão, o tipo machão e superviril (exemplo do cowboy, motorista de caminhão e o esportista) tornaram-se o estilo gay preferencial ${ }_{i}$

6) culto à discoteca e às músicas dançantes e a alguns artistas desse tipo de música: Village People, Gloria 
Gaynor, Donna Summer (anos 1970), Erasure, Pet Shop Boys, Madonna (nos anos 1980), Dee Lite, RuPaul (anos 1990), icones da musica eletrônica nas raves (anos 1990 e 2000).

Macrae (1983, pp. 57 a 60) aponta as seguintes características de comportamento e estilo da cultura do gueto gay:

1) revalorização da palavra lésbica e bicha: assumir esses rótulos sem culpa ou inferioridade é motivo de afirmação, orgulho e disposição de enfrentar o preconceito;

2) repetição dos papéis sexuais de gênero: homem e mulber, ou seja, ativo e passivo, remete, respectivamente, ao bofe e à bicha e, nas mulheres, fanchona e lady. Porém MacRae percebe uma diluição da dicotomia ativo/passivo, deslocando-se essa ênfase de "quem penetra quem" para um relacionamento mais abrangente, principalmente em tempos de AIDS, que explora outras formas de prazer com o parceiro,

3) promiscuidade: compromissos são vistos como liberdade tolhida;

4) "casos abertos": parceiros estabelecem acordos que permitem relacionamentos com terceiros sem ameaça ao "caso";

5) separação de sexo e afeto, acentuada pela proliferação de saunas e black rooms nas boates, em função da necessidade de isolamento para saciar um desejo sexual rapidamente, devido à repressão e à vergonha social de poder ser rotulado como gay em outras esferas sociais;

6) a aventura e o gosto pelo desconhecido são elementos muitos prezados numa "transa", o que rompe as barreiras raciais e de classe social

7) A maioria dos homossexuais tende a discriminar travestis, até mesmo a chamada "bicha pintosa" (sujeito afeminado e preocupado excessivamente com a moda e o visual) tende a sofrer discriminação. Já os travestis alegam que, devido às represálias sociais que suportam, para ser travesti é preciso ser muito "macho". Isso demonstra que já existe uma heterogeneidade no próprio mundo gay, que separa os afeminados, os enrustidos e os assumidos.

\section{REFERÊNCIAS}

BERGER, P. L.; LUCKMANN, T. A construção social da realidade. Petrópolis: Vozes, 2002.

BRAGA JUNIOR, L. F. Caio Fernando Abreu: narrativa e homoerotismo. 2006. Tese (Doutorado em Literatura). Faculdade de Letras, Universidade Federal de Minas Gerais, Belo Horizonte.

BUTLER, J. Problemas de gênero: feminismo e subversão da identidade. Rio de Janeiro: Civilização Brasileira, 2003.

COSTA, J. F. A inocência e o vício: estudos sobre o homoerotismo. Rio de Janeiro: Relume Dumará, 1992.

COSTA, B. P. da. A condição homossexual e a emergência de territorializações. 2002. Dissertação (Mestrado em Geografia) Programa de Pós-Graduação em Geografia, UFRGS, Porto Alegre.

Por uma geografia do cotidiano: território, cultura e homoerotismo na cidade. 2008a. Tese (Doutorado em Geografia) Programa de Pós-Graduação em Geografia, UFRGS, Porto Alegre.

As múltiplas microterritorializações urbanas: o caso das agregações homoeróticas. ANAIS. XV Encontro Nacional de Geógrafos. São Paulo: USP, 2008b.

COSTA, B. P. $d_{i}$ HEIDRICH, A. L. A condição dialética de produção do espaço social: microterritorializações (culturais) urbanas "a favor" e "contra" a sociedade. In: KOSEL, S.; SILVA, J. da C.; GIL FILHO, S. F. Da percepção e cognição à representa- ção: reconstruções teóricas da Geografia Cultural e Humanista. São Paulo: Terceira Imagem ${ }_{i}$ Curitiba: NEER, 2007.

DEBORD, G. A sociedade do espetáculo. Rio de Janeiro: Contraponto, 1997.

DE CERTEAU, M. D. A invenção do cotidiano: artes de fazer. Petrópolis, Vozes, 1994. V. 1.

DELEUZE, G ${ }_{i}$ GUATTARI, F. Mil platôs: capitalismo e esquizofrenia. Vol. 2. Rio de Janeiro: Ed. 34, 1995.

FEATHERSTONE, M. O desmanche da cultura: globalização, pósmodernismo e identidade. São Paulo: SESC $i$ Studio Nobel, 1995.

FOUCAULT, M. Vigiar e punir. Petrópolis: Vozes, 1984.

História da sexualidade: a vontade de saber. Rio de Janeiro: Graal, 1988. V. 1.

Microfísica do poder. Rio de Janeiro: Graal, 1993.

GIDDENS, Anthony. A transformação da intimidade: sexualidade, amor e erotismo nas sociedades modernas. São Paulo: Unesp, 1993.

GOFFMAN, E. Estigma. Rio de Janeiro: Guanabara, 1988.

. A Representação do eu na vida cotidiana. Petrópolis: Vozes, 1996.

GEERTZ, C. A interpretação das culturas. Rio de Janeiro: LTC, 1989

HELLER, A. Sociologia de la vida cotidiana. Barcelona: Península, 1991.

LEFEBVRE, H. Critique de la vie cotidienne. Paris: L'Ache Éditeur A Paris, 1958.

O direito à cidade. São Paulo: Centauro, 2001

A revolução urbana. Belo Horizonte: UFMG, 2004.

MONTEIRO, M. O homoerotismo nas revistas Sui Generis e Homens. In: ENCONTRO DE PESQUISADORES UNIVERSITÁRIOS, 2., 2000, Rio de Janeiro. Literatura e homoerotismo. II Encontro de Pesquisadores Universitários: uma agenda para os estudos gays e lésbicos no Brasil. Rio de Janeiro: UFF, Instituto de Letras, 2000. (Disponivel em $<\underline{\mathrm{http}}: / /$ www.artnet.com. br/ marko/ohomoero. $h t m>$ )

MOSCOVICI, S. Representações sociais: investigação em psicologia social. Petrópolis: Vozes, 2003.

MOTT, L. O sexo proibido: virgens, gays e escravos nas garras da Inquisição. Rio de Janeiro: Papirus, 1988

PRATA, M. R. Da norma disciplinar à iniciativa: os processos subjetivos e os parâmetros normativos contemporâneos. In: PEIXOTO JUNIOR, C. A. (Org.). Formas de subjetivação. Rio de Janeiro: Contra Capa Livraria, 2004.

SIMMEL, G. Requisitos universais e axiomáticos da sociedade. In: FERNADES, F. (Org.) Comunidade e sociedade. São Paulo: Nacional e USP, 1973

SOUZA, M. L. de.; RODRIGUES, G. B. Planejamento urbano e ativismos sociais. São Paulo: UNESP, 2004.

TOURAINE, A. Crítica da modernidade. Petrópolis: Vozes, 1994.

VELHO, G. Subjetividade e sociedade: uma experiência de geração. Rio de Janeiro: Jorge Zahar, 1989.

Individualismo e cultura: notas para uma antropologia da sociedade contemporânea. Rio de Janeiro: Jorge Zahar, 2004.

WALLERSTEIN, I. As agonias do liberalismo: as esperanças para o progresso. In: SADER, E. (Org.). O mundo depois da queda. São Paulo: Paz e Terra, 1995.

WEBER, M. Metodologia das ciências sociais. São Paulo: Cortez, 1995.

WEEKS, J. O corpo e a sexualidade. In: LOURO, G. L.

(Org.). O corpo educado. Belo Horizonte: Autêntica, 1999. 


\section{ABSTRACT}

THIS ARTICLE AIMS TO ANALYZE THE PROCESSES OF HOMOEROTIC MICROTERRITORIALIZATION CHARACTERIZED BY THE PRACTICE OF USING LOCAL SLOW-MOVING STOCK. THESE LOCATIONS THAT WILL UNFOLD ACCORDING TO THE DISCRIMINATION MADE BY SOCIAL INSTITUTIONS AND SOCIETY. THE TEXT, IN HIS ANALYSIS EMPHASIZES THE CONSTRUCTION ON THE PART OF HOMOSEXUALS, AN ENABLER OF A GEOGRAPHY STUDY OF PUBLIC EXPRESSION, SPONTANEITY AND HOMOEROTIC DESIRES IN ORDER TO EFFECTIVE TERRITORIAL COMMUNITY OF EPHEMERAL / TEMPORARY OR STRONG AGGREGATION OF LOCAL, TIME BOUND.

KEYWORDS: TERRITORY AND TERRITORIALITY, HOMOEROTIC MICROTERRITORIALIZATION 
